\title{
Covid-19 and Thyroid: A Scopus-based Bibliometric Assessment of Research Output
}

\author{
Devi Dayal' ${ }^{1,}$, BM Gupta ${ }^{2}$, Madhu Bansal', Pamali Mahasweta Nanda' \\ 'Postgraduate Institute of Medical Education and Research, Department of Pediatrics, Chandigarh, INDIA. \\ ${ }^{2}$ Formerly with CSIR-National Institute of Science, Technology and Development Studies, New Delhi, Delhi, INDIA. \\ 3Panjab University, Department of Mathematics, Chandigarh, INDIA.
}

\begin{abstract}
Introduction: A bibliometric assessment of coronavirus disease 2019 (Covid-19)-related thyroid research is unavailable. Materials and Methods: We searched Elsevier's Scopus database for publications on Covid-19 and thyroid disease up to August 18, 2021, using a predefined search strategy. The data were analyzed by publication characteristics, the most active countries, institutions, authors, journals, citations, and research trends. Results: The global publications totaled 599; 446 (74.4\%) were original articles. Only $18.0 \%$ (108) were funded, but these received higher citations per paper (CPP) than the non-funded publications (average CPP 14.8 versus 9.8). Of the 97 countries that participated in the research, the USA, Italy, India, and China were the most productive, whereas China, Germany, UK, and the USA were the most impactful. The studied patient population groups were "Adults" (50.5\%), "Middle-Aged" (33.7\%), "Aged" (29.3\%), "Children" (7.8\%), and "Adolescents" (6.5\%). The research organizations and authors numbered 272 and 404, respectively. The most productive organizations were Universita Degli Studi Napoli, Italy, Harvard Medical School, USA, and Universita Degli Studi Milano, Italy. The most productive authors were G. Troncone, L. Glovanella, and G. Anedda. The top productive journals were Endocrine, Journal of Endocrine Investigation,
\end{abstract}

and Frontiers in Endocrinology. Only 22 (3.6\%) were highly-cited (average CPP 141.8). Conclusion: The Covid-19 research concerning thyroid disorders has been largely conducted in the USA and Europe with contributions from China and India. There is a need to foster collaboration between high- and low-income countries for formulating better strategies to tackle thyroidrelated morbidities in Covid-19. Additionally, such research should involve younger age groups.

Key words: Coronavirus disease 2019, Thyroid diseases, Co-morbidities, Children, Adults.

\section{Correspondence}

Prof. Devi Dayal,

Endocrinology and Diabetes Unit, Department of Pediatrics, Advanced Pediatrics Center, Postgraduate Institute of Medical Education and Research, Chandigarh-160012, INDIA.

Email id: drdevidayal@gmail.com

DOI: 10.5530/jyp.2021.13s.76

\section{INTRODUCTION}

Coronavirus disease 2019 (Covid-19) pandemic is an enormous global health problem. It has resulted in significant morbidity and mortality and worldwide disruption in healthcare services. ${ }^{1,2}$ The pandemic forced the medical fraternity to quickly formulate guidelines for patients with underlying medical conditions and adopt new methods of healthcare delivery. ${ }^{3-5}$ The main reason for morbidity and mortality in Covid-19 is its severely damaging effects on the patients' respiratory system. However, the disease is now known to cause considerable damage to other vital organs and the endocrine system. While diabetes remains the most common association, other endocrine dysfunction such as adrenal insufficiency, low T3 and low TSH syndrome, hyperprolactinemia, and hypopituitarism also occur in a significant proportion of patients with moderate or severe Covid-19.6-8 A recent hospital-based study found thyroid dysfunction in almost one-fourth of Covid-19 patients who underwent hormonal profiles. ${ }^{7}$ Indeed, virtually all kinds of non-neoplastic thyroid diseases such as Hashimoto's thyroiditis, Graves' disease, subacute thyroiditis, Low T3 and low T4 syndrome, etc., have been reported to complicate Covid-19. ${ }^{9}$ Although causality by the virus has been strongly implicated in all these thyroid disorders, several aspects of thyroid involvement in Covid-19 remain unexplained. ${ }^{10}$ Extensive research is thus still needed in order to manage thyroid dysfunction in patients with Covid-19 better. The first step to further research is to assess previously conducted research and identify the gaps and hotspots, researchers, organizations, and funding agencies that share research interests. This is usually achieved through scientometric or bibliometric studies. ${ }^{11}$ There is thus a need for conducting a bibliometric assessment of research output on thyroid disorders in relation to Covid-19.

Previous bibliometric assessments of thyroid diseases were either conducted prior to the Covid-19 pandemic or did not separately assess the literature concerning Covid-19 and thyroid. ${ }^{12-14}$ A bibliometric study published recently on global publication output on Covid-19 did not contain information on thyroid publications. ${ }^{15}$ Of the various endocrine problems related to Covid-19, only diabetes research has been assessed bibliometrically. ${ }^{16}$ We thus planned a similar study to address the lack of a comprehensive assessment of published literature on thyroid disorders concerning Covid-19.

\section{Objectives}

The study aimed to provide a quantitative and qualitative assessment of global research on thyroid diseases in relation to the Covid-19 pandemic based on publications indexed in Elsevier's Scopus database during 2020-2021. The analysis included publications growth, research collaborations, funding support, citation impact, top organizations, authors, journals, and characteristics of highly-cited papers (HCPs).

\section{MATERIALS AND METHODS}

The publications on the theme "Covid-19 \& Thyroid" were identified from the Elsevier's Scopus database (https://www.scopus.com), using 
two sets of keywords "Covid-19" and "Thyroid" in field tags, "Keyword" or "Title" (Article Title) and limiting the search to 2020-2021. The search string is shown below:

TITLE ( "Covid 19" or "2019 novel coronavirus" or "coronavirus 2019" or "coronavirus disease 2019" or "2019-novel CoV" or "2019 ncov" or covid 2019 or covid19 or "corona virus 2019" or ncov-2019 or ncov2019 or "nCoV 2019" or 2019-ncov or covid-19 or "Severe acute respiratory syndrome coronavirus 2" or "SARS-CoV-2") or KEY ( "Covid 19" or "2019 novel coronavirus" or "coronavirus 2019" or "coronavirus disease 2019" or "2019-novel CoV" or "2019 ncov" or covid 2019 or covid19 or "corona virus 2019" or ncov-2019 or ncov2019 or "nCoV 2019" or 2019-ncov or covid-19 or "Severe acute respiratory syndrome coronavirus 2" or "SARS-CoV-2" ) and Key (thyroid* or hyperthyroid* or hypothyroid*).

The search yielded 599 records, which were further analyzed using additional analytical provisions in the Scopus database. Publication characteristics were tabulated, including titles, authors, co-cited authors, journal sources, keywords, affiliations, countries, or regions. Co-cited authors mean that the authors have been cited together. To resolve the issue of synonyms or homonyms in authors' names, we used other specific fields such as affiliations. To assess the quality of publications, various indicators such as citations per paper (CPP), relative citation index (RCI), and Hirsch index (HI) were used. Publications that had received more than 50 citations were considered HCPs. Citations to publications were counted from the date of their publication till August 18, 2021. We also utilized VOSviewer (version 1.6.14) software to analyze the collaborations and keywords clusters.

\section{RESULTS}

\section{The general profile of publications}

The total number of publications was 599; 293 and 306 during 2020 and 2021, respectively. These publications received 5878 citations, averaging 9.8 CPP. The funded publications $(108,18.0 \%)$ received 1604 citations, averaging 14.8 CPP. The leading global funding agencies were the National Institutes of Health (15 papers), the US Department of Health and Human Services (11 papers), the National Natural Science Foundation of China (10 papers), Conselho Nacional de Desenvolvimento Científico Tecnológico (7 papers) and National Cancer Institute (7 papers).

The broad subject-wise distribution showed the largest share of publications in Medicine (92.8\%), followed by Biochemistry, Genetics and Molecular Biology (25.8\%), Immunology and Microbiology (7.8\%), Pharmacology, Toxicology and Pharmaceutics (3.3\%), and Neurosciences (3.0\%). An overlap was observed in subject areas. In terms of impact, publications on Biochemistry, Genetics and Molecular Biology registered the highest, and Immunology and Microbiology recorded the least CPP of 11.1 and 5.7, respectively. The majority of the studies $(234,39 \%)$ were on the treatment of thyroid disorders, followed by clinical aspects (157, $26.2 \%)$, complications (110, 18.3\%), pathophysiology (103, 17.2\%), epidemiology $(88,14.7 \%)$ and risk factors $(71,11.8 \%)$. Pathophysiology and epidemiology studies registered the highest and the least CPP of 15.9 and 7.1 , respectively.

On classifying the publications by age group of the patient population, it was observed that studies related to "Adults" accounted for the largest share of publications (50.5\%), followed by "Middle-Aged" (33.7\%), "Aged" (29.3\%), "Children" (7.8\%) and "Adolescents" (6.5\%). We also identified forty-four significant keywords with the frequency of appearance varying from 30 to 325 , which broadly indicate the trends of research on our study's theme (Figure 1).

\section{The top contributing countries}

Eighty-seven countries unevenly participated in global research on thyroid disorders in Covid-19; 61 countries contributed 1-5 papers each, nine countries 6-10 papers each, 15 countries 11-50 papers each, and two countries 123-129 papers. The top 10 countries together contributed $86.6 \%$ of publications. USA and Italy made the largest contributions ( $21.5 \%$ and $20.5 \%$ share), followed by India, China, and UK $(8.3 \%, 8.0 \%$, and $7.01 \%$ respectively). Four of the top 10 countries registered CPP and RCI higher than their group average of 15.0 and 1.5, respectively, and were considered more impactful (Table 1). The collaborative linkages between the top 10 countries are shown in Figure 2.

\section{Top research organizations}

The contribution of 272 organizations that participated in the thyroid-Covid-19 research was uneven; 247 contributed 1-5 papers each, 20 organizations 6-10 papers each, and six organizations 11-14 papers each. The top 25 organizations contributed 213 (35.5\%) publications and $3557(60.5 \%)$ citations. The contributions of 11 organizations were higher than the group average of 8.5 , while six organizations registered $\mathrm{CPP}$ and RCI above the group average of 16.7 and 1.7, respectively. Table 2

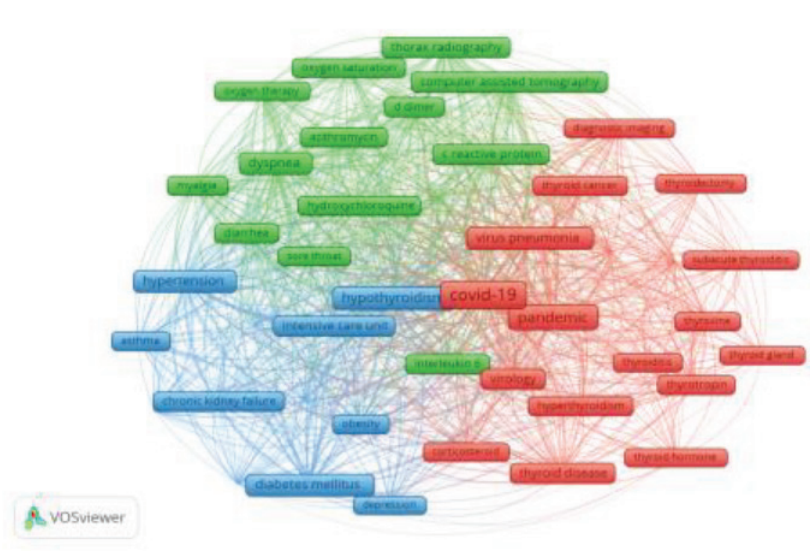

Figure 1: Cooccurrence network of 44 significant keywords arranged in three clusters (red, green \& blue), having 909 links and total link strength of 13020 . The thickness of nodes depicts their frequency of occurrence.

\section{Table 1: The most productive and influential countries in} Covid-19-thyroid research.

\begin{tabular}{clcccccccc}
\hline S. no. & Country & TP & TC & CPP & HI & ICP & \%ICP & $\%$ TP & RCI \\
\hline 1 & USA & 129 & 2155 & 16.7 & 17 & 40 & 31.0 & 21.5 & $1.7^{*}$ \\
2 & Italy & 123 & 1557 & 12.6 & 19 & 35 & 28.4 & 20.5 & 1.2 \\
3 & India & 50 & 242 & 4.8 & 8 & 10 & 20.0 & 8.3 & 0.5 \\
4 & China & 48 & 1453 & 30.2 & 11 & 10 & 20.8 & 8.0 & $3.0^{*}$ \\
5 & UK & 42 & 852 & 20.3 & 11 & 20 & 47.6 & 7.0 & $2.0^{*}$ \\
6 & Iran & 28 & 193 & 6.9 & 5 & 5 & 17.8 & 4.6 & 0.7 \\
7 & Germany & 26 & 776 & 29.8 & 9 & 4 & 15.3 & 4.3 & $3.0^{*}$ \\
8 & Turkey & 26 & 89 & 3.4 & 4 & 4 & 15.3 & 4.3 & 0.3 \\
9 & Spain & 25 & 177 & 7.0 & 8 & 12 & 48.0 & 4.1 & 0.7 \\
10 & France & 22 & 324 & 14.7 & 9 & 11 & 50.0 & 3.6 & 1.5 \\
& Total & 519 & 7818 & 15.0 & 10.1 & 151 & 29.0 & 86.6 & 1.5 \\
\hline
\end{tabular}

${ }^{*}$ more impactful than others

Abbreviations: TP, total papers; TC, total citations; CPP, citations per paper; ICP, international collaborative papers; HI, H-Index; RCI, relative citation index. 


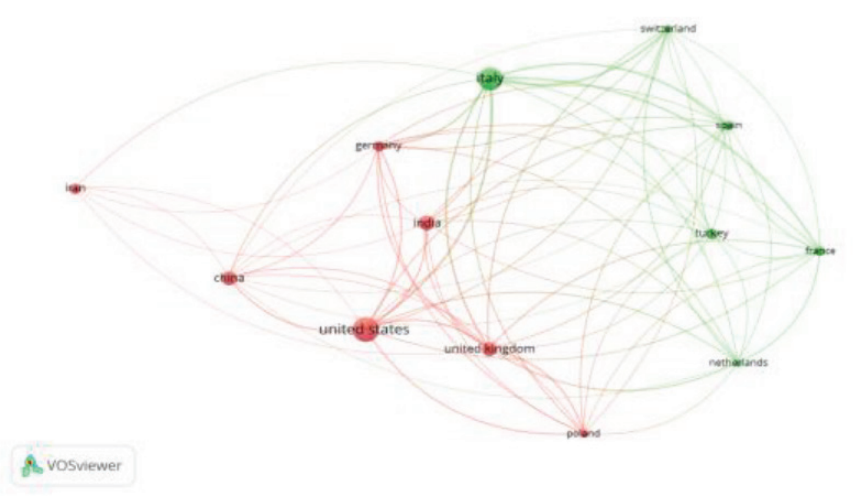

Figure 2: The collaborative network of the most productive countries. The thickness of the node represents productivity. The countries are arranged in 2 clusters (Red \& Green), having 72 links and total link strength of 230 .

Table 2: The most productive and most influential organizations in thyroid-Covid-19 research.

\begin{tabular}{|c|c|c|c|c|c|c|c|}
\hline S.no. & Organization & TP & TC & CPP & $\mathrm{HI}$ & ICP (\%) & $\mathrm{RCl}$ \\
\hline \multicolumn{8}{|c|}{ Top 10 most productive organizations } \\
\hline 1 & $\begin{array}{l}\text { Universita degli Studi di Napoli } \\
\text { II, Italy }\end{array}$ & 14 & 504 & 36.0 & 5 & $6(42.8)$ & 3.6 \\
\hline 2 & Harvard Medical School, USA & 13 & 182 & 14.0 & 6 & $5(38.4)$ & 1.4 \\
\hline 3 & $\begin{array}{l}\text { Universita degli Studi di } \\
\text { Milano, Italy }\end{array}$ & 13 & 177 & 13.6 & 7 & $6(46.1)$ & 1.4 \\
\hline 4 & $\begin{array}{l}\text { Universita degli Studi di } \\
\text { Messina, Italy }\end{array}$ & 12 & 57 & 4.7 & 3 & $5(41.6)$ & 0.4 \\
\hline 5 & $\begin{array}{l}\text { Sapienza Universita di Roma, } \\
\text { Italy }\end{array}$ & 12 & 79 & 6.5 & 4 & $2(16.6)$ & 0.6 \\
\hline 6 & $\begin{array}{l}\text { Massachustts General Hospital, } \\
\text { USA }\end{array}$ & 11 & 40 & 3.6 & 4 & $6(54.5)$ & 0.3 \\
\hline 7 & $\begin{array}{l}\text { Tehran University of Medical } \\
\text { Sciences, Iran }\end{array}$ & 10 & 128 & 12.8 & 4 & $0(0.0)$ & 1.3 \\
\hline 8 & PGIMER-Chandigarh, India & 9 & 113 & 12.5 & 4 & $1(11.1)$ & 1.2 \\
\hline 9 & $\begin{array}{l}\text { Huazhong University of Science } \\
\& \text { Technology, China }\end{array}$ & 9 & 535 & 59.4 & 3 & $1(11.1)$ & 6.0 \\
\hline 10 & $\begin{array}{l}\text { Universita degli Studi della } \\
\text { Campania Luigi Vanvitelli, Italy }\end{array}$ & 9 & 80 & 8.9 & 4 & $4(44.4)$ & 0.9 \\
\hline \multicolumn{8}{|c|}{ Top 10 most impactful organizations } \\
\hline 1 & $\begin{array}{l}\text { Universita Cattolica de Sacro } \\
\text { Cuore, Campus di Roma, Italy }\end{array}$ & 7 & 472 & 67.4 & 4 & $2(28.5)$ & 6.8 \\
\hline 2 & $\begin{array}{l}\text { Memorial Sloan-Kettering } \\
\text { Cancer Center, USA }\end{array}$ & 6 & 397 & 66.17 & 4 & $3(50.0)$ & 6.7 \\
\hline 3 & $\begin{array}{l}\text { Huazhong University of Science } \\
\& \text { Technology, China }\end{array}$ & 9 & 535 & 59.4 & 3 & $1(11.1)$ & 6.0 \\
\hline 4 & $\begin{array}{l}\text { Universita degli Studi di } \\
\text { Napoli II, Italy }\end{array}$ & 14 & 504 & 36.0 & 5 & $6(42.8)$ & 3.6 \\
\hline 5 & $\begin{array}{l}\text { University of Pennsylvania, } \\
\text { Italy }\end{array}$ & 6 & 161 & 26.8 & 5 & $3(50.0)$ & 2.7 \\
\hline 6 & $\begin{array}{l}\text { Universitats Spital Zurich, } \\
\text { Switzerland }\end{array}$ & 7 & 154 & 22.0 & 4 & $5(71.4)$ & 2.2 \\
\hline 7 & Tongji Medical College, China & 7 & 112 & 16.0 & 2 & $0(0.0)$ & 1.6 \\
\hline 8 & Harvard Medical School, USA & 13 & 182 & 14.0 & 6 & $5(38.4)$ & 1.4 \\
\hline 9 & $\begin{array}{l}\text { Universita degli Studi di } \\
\text { Milano, Italy }\end{array}$ & 13 & 177 & 13.6 & 7 & $6(46.1)$ & 1.4 \\
\hline 10 & $\begin{array}{l}\text { Tehran University of Medical } \\
\text { Sciences, Iran }\end{array}$ & 10 & 128 & 12.8 & 4 & $0(0.0)$ & 1.3 \\
\hline
\end{tabular}

Abbreviations: TP, total papers; TC, total citations; CPP, citations per paper; ICP, international collaborative papers; HI, H-Index; RCI, relative citation index. shows the relative contribution of the ten most productive and ten most impactful organizations.

\section{Most prolific and influential authors}

Of the 404 authors who participated unevenly in research, 286 contributed one paper each, 68 contributed two papers each, 33 published three papers each, 15 contributed four papers each. One each published 5 and 7 papers. Table 3 lists the ten most productive and the ten most impactful authors.

\section{Most productive journals}

Five hundred ninety-eight papers were published as journal articles and one as conference proceedings. Of the 181 journals that participated, 170 journals published 1-5 papers each, eight published 6-10 papers each, and three published 11-19 papers each. The top 10 journals contributed $27.6 \%$ of total publications in this research field. The profiles of the most active and the most influential journals are shown in Table 4.

\section{Highly cited publications}

Only $22(3.6 \%)$ publications were HCPs which cumulatively received 3121 citations, averaging 141.8 CPP. Fourteen papers received 51 to 92 citations, four received 101-140 citations, and four received 287-431 citations. The largest number of HCPs were contributed by the USA, followed by China ( 6 papers) and Italy ( 5 papers). The majority (19 out of 22) of the HCPs were collaborative endeavors; 12 were national, and seven were international collaborative.

\section{DISCUSSION}

Our analysis reveals that the quantity of research on thyroid disorders in relation to Covid-19 was much lower than other endocrine problems such as diabetes, recently assessed bibliometrically. The number of publications was approximately 34 per month for thyroid compared to about 84 per month for diabetes. ${ }^{16}$ This was probably related to the lower contribution to morbidity and mortality and ease of management of thyroid disorders as compared to diabetes in patients with Covid-19. ${ }^{6-9}$ In addition, almost $40 \%$ of the research was conducted in two high-income countries, i.e., the USA and Italy. Although several low- and middle-income countries such as Brazil, Libya, and African countries have reported a high prevalence of thyroid disorders in the immediate pre-Covid era, only China and India could manage to contribute significantly to thyroid research concerning Covid-19. ${ }^{17}$ But despite being ranked third in productivity, the quality of Indian research as indicated by CPP and RCI was much lower compared to other highly productive countries. A significant reason could be the disparity in the researchers' approach and the funding devoted to Covid-19 research in high- compared to low-income countries. While the high-income countries approached Covid-19 research that enabled them to develop priorities to inform future research studies and funding decisions, such an approach was lacking in the low-income countries. ${ }^{18}$ The redistribution of resources during the Covid-19 pandemic meant little funding support available for research in low-income countries. Even before Covid-19, resource crunch for research is generally experienced in low- and middle-income countries and leads to lower quality of research. ${ }^{19}$ It is well known that research funding is associated with improvement in the quality of research. ${ }^{20}$ A recent bibliometric analysis showed that the CPP of funded publications was 4-times higher than non-funded publications (77.2 versus 18.6). ${ }^{21}$

A notable finding of our analysis was the low quantity of publications on the pediatric patient population compared to other age groups. This is understandable as the number of affected children and the severity of 
Table 3: The most prolific and the most influential authors in Thyroid-Covid-19 research.

\begin{tabular}{|c|c|c|c|c|c|c|c|c|}
\hline S.no. & Author & Affiliation & TP & TC & CPP & $\mathrm{HI}$ & ICP (\%) & $\mathrm{RC}$ \\
\hline \multicolumn{9}{|c|}{ Ten most productive authors } \\
\hline 1 & G.Troncone & $\begin{array}{l}\text { University degli } \\
\text { Studi di Napoli } \\
\text { Federico 11, Italy }\end{array}$ & 7 & 53 & 7.5 & 4 & $3(42.8)$ & 0.8 \\
\hline 2 & L.Glovanella & $\begin{array}{l}\text { University } \\
\text { of Zagreb, } \\
\text { Switzerland }\end{array}$ & 5 & 16 & 3.2 & 2 & $5(100.0)$ & 0.3 \\
\hline 3 & G.Anedda & $\begin{array}{l}\text { Universita degli } \\
\text { Studi di Cagliari, } \\
\text { Italy }\end{array}$ & 4 & 4 & 1.0 & 1 & $0(0.0)$ & 0.1 \\
\hline 4 & C.Bellevicine & $\begin{array}{l}\text { University degli } \\
\text { Studi di Napoli } \\
\text { Federico 11, Italy }\end{array}$ & 4 & 44 & 11.0 & 3 & $1(25.0)$ & 1.2 \\
\hline 5 & P.G.Calo & $\begin{array}{l}\text { Universita degli } \\
\text { Studi di Cagliari, } \\
\text { Italy }\end{array}$ & 4 & 4 & 1.0 & 1 & $0(0.0)$ & 0.1 \\
\hline 6 & G.L.Canu & $\begin{array}{l}\text { Universita degli } \\
\text { Studi di Cagliari, } \\
\text { Italy }\end{array}$ & 4 & 4 & 1.0 & 1 & $0(0.0)$ & 0.1 \\
\hline 7 & F.Cappellacci & $\begin{array}{l}\text { Universita degli } \\
\text { Studi di Cagliari, } \\
\text { Italy }\end{array}$ & 4 & 4 & 1.0 & 1 & $0(0.0)$ & 0.1 \\
\hline 8 & L.Chiovato & $\begin{array}{l}\text { Instituti Clinici } \\
\text { Scientifici } \\
\text { Maugeri Italy }\end{array}$ & 4 & 36 & 9.0 & 3 & $0(0.0)$ & 1.0 \\
\hline 9 & P.Del Rio & $\begin{array}{l}\text { University of } \\
\text { Parma, Parma, } \\
\text { Italy }\end{array}$ & 4 & 6 & 1.5 & 2 & $1(25.0)$ & 0.1 \\
\hline 10 & A.Glustina & $\begin{array}{l}\text { Universita Vita- } \\
\text { Salute Raffaele, } \\
\text { Italy } \\
\end{array}$ & 4 & 62 & 15.5 & 4 & $2(50.0)$ & 1.7 \\
\hline \multicolumn{9}{|c|}{ Ten most impactful authors } \\
\hline 1 & A.Glustina & $\begin{array}{l}\text { Universita Vita- } \\
\text { Salute Raffaele, } \\
\text { Italy }\end{array}$ & 4 & 62 & 15.5 & 4 & $2(50.0)$ & 1.7 \\
\hline 2 & A.B.Grossman & $\begin{array}{l}\text { University of } \\
\text { Oxford, UK }\end{array}$ & 4 & 53 & 13.2 & 3 & $4(100.0)$ & 1.4 \\
\hline 3 & C.Bellevicine & $\begin{array}{l}\text { University degli } \\
\text { Studi di Napoli } \\
\text { Federico 11, Italy }\end{array}$ & 4 & 44 & 11.0 & 3 & $1(25.0)$ & 1.2 \\
\hline 4 & E.Vigliar & $\begin{array}{l}\text { University degli } \\
\text { Studi di Napoli } \\
\text { Federico 11, Italy }\end{array}$ & 4 & 44 & 11.0 & 3 & $1(25.0)$ & 1.2 \\
\hline 5 & R.M Ruggeri & $\begin{array}{l}\text { Universita degli } \\
\text { Studi di Messina, } \\
\text { Italy }\end{array}$ & 4 & 40 & 10.0 & 2 & $3(75.0)$ & 1.1 \\
\hline 6 & W.S.Chow & $\begin{array}{l}\text { University of } \\
\text { Hong KongK }\end{array}$ & 3 & 30 & 10.0 & 2 & $0(0.0)$ & 1.1 \\
\hline 7 & L.Chiovato & $\begin{array}{l}\text { Instituti Clinici } \\
\text { Scientifici } \\
\text { Maugeri Italy }\end{array}$ & 4 & 36 & 9.0 & 3 & $0(0.00$ & 1.0 \\
\hline 8 & K.Esposito & $\begin{array}{l}\text { E.O. Ospedali } \\
\text { Galliera, Genoa, } \\
\text { Italy }\end{array}$ & 3 & 27 & 9.0 & 2 & $2(66.6)$ & 1.0 \\
\hline 9 & L.Croce & $\begin{array}{l}\text { Instituti Clinici } \\
\text { Scientifici } \\
\text { Maugeri Italy }\end{array}$ & 3 & 27 & 9.0 & 2 & $0(0.0)$ & 1.0 \\
\hline 10 & G.Troncone & $\begin{array}{l}\text { University degli } \\
\text { Studi di Napoli } \\
\text { Federico 11, Italy }\end{array}$ & 7 & 53 & 7.5 & 4 & $3(42.8)$ & 0.8 \\
\hline
\end{tabular}

Abbreviations: TP, total papers; TC, total citations; CPP, citations per paper; ICP, international collaborative papers; HI, H-Index; RCI, relative citation index.
Table 4: The most active and the most influential journals in Covid-19-thyroid research.

\begin{tabular}{|c|c|c|c|c|}
\hline S.no. & Journal & TP & TC & CPP \\
\hline \multicolumn{5}{|c|}{ Ten most prolific journals } \\
\hline 1 & Endocrine & 19 & 116 & 6.11 \\
\hline 2 & Journal of Endocrine Investigation & 18 & 251 & 13.94 \\
\hline 3 & Frontiers in Endocrinology & 11 & 39 & 3.55 \\
\hline 4 & BMJ Case Reports & 10 & 46 & 4.60 \\
\hline 5 & $\begin{array}{l}\text { Journal of Clinical Endocrinology \& } \\
\text { Metabolism }\end{array}$ & 8 & 180 & 22.50 \\
\hline 6 & Journal of Medical Virology & 8 & 51 & 6.38 \\
\hline 7 & Head \& Neck & 7 & 33 & 4.71 \\
\hline 8 & Annals of Medicine \& Surgery & 6 & 3 & 0.50 \\
\hline 9 & $\begin{array}{l}\text { Diabetes \& Metabolic Syndrome. Clinical } \\
\text { Research \& Reviews }\end{array}$ & 6 & 45 & 7.50 \\
\hline 10 & European Journal of Endocrinology & 6 & 95 & 15.83 \\
\hline \multicolumn{5}{|c|}{ Ten most impactful journals } \\
\hline 1 & Travel Medicine \& Infectious Diseases & 6 & 191 & 31.83 \\
\hline 2 & $\begin{array}{l}\text { Journal of Clinical Endocrinology \& } \\
\text { Metabolism }\end{array}$ & 8 & 180 & 22.50 \\
\hline 3 & European Journal of Endocrinology & 6 & 95 & 15.83 \\
\hline 4 & Journal of Endocrine Investigation & 18 & 251 & 13.94 \\
\hline 5 & International Journal of Infectious Diseases & 5 & 68 & 13.60 \\
\hline 6 & Reviews in Endocrine \& Metabolic Disorders & 4 & 51 & 12.75 \\
\hline 7 & $\begin{array}{l}\text { International Journal of Gynecology \& } \\
\text { Obstetrics }\end{array}$ & 4 & 39 & 9.75 \\
\hline 8 & Ear Nose \& Throat Journal & 4 & 31 & 7.75 \\
\hline 9 & $\begin{array}{l}\text { Diabetes \& Metabolic Syndrome: Clinical } \\
\text { Research \& Reviews }\end{array}$ & 6 & 45 & 7.50 \\
\hline 10 & Journal of the Endocrine Society & 4 & 28 & 7.00 \\
\hline
\end{tabular}

Abbreviations: TP, total papers; TC, total citations; CPP, citations per paper.

Covid-19 was lower during the previous Covid-19 waves..22 Nevertheless, in view of the subsequent Covid-19 waves likely to affect more children, there is a need to be prepared with research strategies aimed at mitigating the effects of co-morbidities such as thyroid disease in addition to general pandemic countermeasures such as public health messaging and guidance for primary care. ${ }^{23}$ In this regard, high-volume pediatric centers and researchers already engaged in thyroid research will have to play an active role, specifically in low-income countries. ${ }^{24-28}$

We used a single database for the current analysis, similar to most previous scientometric studies. ${ }^{29,30}$ Because of Scopus's broader content coverage, search analysis tools, citation accuracy, and funding information than other databases, most bibliometric analyses prefer to utilize Scopus. ${ }^{31}$ But Scopus does not cover all the published content, so our study may have missed data and citations on the theme of our study. A simultaneous search in Scopus, PubMed, and Web of Science may have captured additional data but is very cumbersome to carry out. ${ }^{32}$ Despite the limitation, our analysis could identify the research gaps and trends in thyroid research in relation to Covid-19 and suggest the potential use of our findings. The study thus provides a framework for authors, organizations, and countries to focus on critical areas of future research in this field.

\section{CONCLUSION}

The Covid-19 research in relation to thyroid disorders has been largely conducted in the USA and Europe with substantial contributions from China and India. The studies mainly focused on the treatment and clinical 
spectrum of thyroid disease in Covid-19. There is a need to foster collaboration between high-income and low-income countries for formulating better research strategies to combat thyroid-related morbidities in Covid-19. There is a need to prioritize research involving children and adolescents because of a possible future Covid-19 wave speculated to affect children disproportionately.

\section{CONFLICT OF INTEREST}

The authors declare no conflict of interest.

\section{REFERENCES}

1. Pieper S. Covid-19: salt in the wound of health care inequality and the cause of a new healthcare disparity. Phys Assist Clin. 2021 Aug 13. doi: 10.1016/j. cpha.2021.08.009 [Epub ahead of print]. PMID 34405121.

2. Dayal D, Gupta S, Raithatha D, Jayashree M. Missing during Covid-19 lockdown: children with onset of type 1 diabetes. Acta Paediatr. 2020;109(10):2144-6. doi: 10.1111/apa.15443, PMID 32575149

3. Dayal D. We urgently need guidelines for managing Covid-19 in children with comorbidities. Acta Paediatr. 2020;109(7):1497-8. doi: 10.1111/apa.15304, PMID 32279351.

4. Dayal D, Yadav A. Covid-19: Considerations for children and adolescents with diabetes. J Diabetol. 2020;11(3):126-30. doi: 10.4103/JOD.JOD_40_20.

5. Rohilla L, Walia P, Kaur G, Gupta S, Gupta A, Yadav A, et al. Smartphone app to deliver virtual follow-up care for children with Type 1 diabetes during the Covid-19 pandemic: experience in a resource-limited setup. IJDE. 2021;6(2):64-8. doi: 10.11648/j.ijde.20210602.12

6. Bonansea TCP, Santos LPD, Zintl K, Souza ACDS. Diabetes in the Covid-19 pandemic era. Rev Assoc Med Bras (1992). 2021;67Suppl(Suppl 1);Suppl 1:157-62. doi: 10.1590/1806-9282.67.Suppl1.20200814, PMID 34406303.

7. Kumar B, Gopalakrishnan M, Garg MK, Purohit P, Banerjee M, Sharma P, et al. Endocrine dysfunction among patients with Covid-19: A single-center experience from a tertiary hospital in India. Indian J Endocrinol Metab. 2021;25(1):14-9. doi: 10.4103/ijem.IJEM_577_20, PMID 34386388.

8. Frara S, Loli P, Allora A, Santini C, di Filippo L, Mortini P, et al. Covid-19 and hypopituitarism. Rev Endocr Metab Disord. 2021 Aug 13. doi: 10.1007/s11154021-09672-y [Epub ahead of print]. PMID 34387832.

9. Inaba H, Aizawa T. Coronavirus disease 2019 and the thyroid - progress and perspectives. Front Endocrinol (Lausanne). 2021;12:708333. doi: 10.3389/ fendo.2021.708333.

10. Lisco G, De Tullio A, Jirillo E, Giagulli VA, De Pergola G, Guastamacchia E, Triggiani V. Thyroid and Covid-19: a review on pathophysiological, clinical and organizational aspects. J Endocrinol Invest. 2021;44(9):1801-14. doi: 10.1007/s40618021-01554-z, PMID 33765288.

11. Cooper ID. Bibliometrics basics. J Med Libr Assoc. 2015;103(4):217-8. doi: 10.3163/1536-5050.103.4.013, PMID 26512226.

12. Gupta BM, Ahmed KKM, Gupta R. Thyroid Research in India: A Scientometric Assessment of Publications Output during 2007-16. IJMEDPH. 2017;7(3):134-41. doi: 10.5530/ijmedph.2017.3.28.

13. Dayal D, Gupta BM. Pediatric hyperthyroidism research: A scientometric assessment of global publications during 1990-2019. Thyroid Res Pract. 2020;17(3):134-40. doi: 10.4103/trp.trp_67_20.

14. Dayal D, Gupta BM, Gupta A. Thyroid disorders in children and adolescents: systematic mapping of global research over the past three decades. Thyroid Res Pract. 2021;18(1):23-30. doi: 10.4103/trp.trp_5_21.

15. Gupta B, Dhawan S, Mueen Ahmed K, Mamdapur GM. Global Research on Covid-19 Disease: A Scientific Assessment of Publications during 2020-21. IJMEDPH. 2021;11(2):76-84. doi: 10.5530/ijmedph.2021.2.14.
16. Gupta BM, Pal R, Rohilla L, Dayal D. Bibliometric analysis of diabetes research in relation to the Covid-19 pandemic. J Diabetol. 2021;12(3):350-6.doi:10.4103/ JOD.JOD_30_21.

17. Taylor PN, Albrecht D, Scholz A, Gutierrez-Buey G, Lazarus JH, Dayan CM, Okosieme OE. Global epidemiology of hyperthyroidism and hypothyroidism. Nat Rev Endocrinol. 2018;14(5):301-16. doi: 10.1038/nrendo.2018.18, PMID 29569622.

18. Adeloye D, Elneima O, Daines L, Poinasamy K, Quint JK, Walker S, et al. The long-term sequelae of Covid-19: an international consensus on research priorities for patients with pre-existing and new-onset airways disease. Lancet Respir Med. 2021 Aug 17;21:S2213-2600. doi: 10.1016/S2213-2600(21)00286-1 [Epub ahead of print]. PMID 34416191.

19. Lakhotia SC. Research fund crunch, real or created, is hitting India's Academia on the Wrong Side. Proc Indian Natl Sci Acad. 2018;98(3):545-7. doi: 10.16943/ ptinsa/2018/49475.

20. Agarwal R, Tu W. NIH Funding, Research productivity, and scientific impact: a 20-year study. J Gen Intern Med. 2021 Mar 2. doi: 10.1007/s11606-021-06659-y [Epub ahead of print]. PMID 33655385.

21. Gupta BM, Sikka P, Gupta S, Dayal D. Indian research in gestational diabetes mellitus during the past three decades: A scientometric analysis. J Obstet Gynaecol India. 2021;71(3):254-61. doi: 10.1007/s13224-021-01444-7, PMID 34408344.

22. Wong JJM, Abbas Q, Chuah SL, Malisie RF, Pon KM, Katsuta T, et al. Comparative analysis of pediatric Covid-19 infection in Southeast Asia, South Asia Japan, and China. Am J Trop Med Hyg. 2021 Jun 15:tpmd210299. doi: 10.4269/ ajtmh.21-0299 [Epub ahead of print]. PMID 34129517.

23. Shanmugavadivel D, Liu JF, Gilhooley C, Elsaadany L, Wood D. Changing patterns of emergency paediatric presentations during the first wave of Covid-19: learning for the second wave from a UK tertiary emergency department. BMJ Paediatr Open. 2021;5(1):e000967. doi: 10.1136/bmjpo-2020-000967, PMID 34192192.

24. Dayal D, Naganur SH, Siakia BK, Singh B. Thyroid dysfunction and autoantibodies in first degree relatives of North Indian children with autoimmune thyroiditis. Thyroid Res Pract. 2015;12(3):96-9. doi: 10.4103/0973-0354.157931.

25. Dayal D, Hansdak N, Vir D, Gupta A, Bakshi J. Hearing impairment in children with permanent congenital hypothyroidism: data from Northwest India. Thyroid Res Pract. 2016;13(2):67-70. doi: 10.4103/0973-0354.183278.

26. Dayal D, Prasad R, Bhunwal S, Kumar R, Kumar RM, Sodhi KS. Spectrum of extrathyroidal congenital malformations in a cohort of North Indian children with permanent primary congenital hypothyroidism. Thyroid Res Pract. 2017;14(1):8-11. doi: 10.4103/0973-0354.200559.

27. Cautha S, Dayal D, Sachdeva N, Badal D, Attri SV, Sodhi KS. Serum concentrations of interleukin-17A but not interleukin-17F are elevated in children with recent-onset Hashimoto's thyroiditis. Thyroid Res Pract. 2018;15(3):128-31. doi: 10.4103/trp.trp_22_18.

28. Dayal D, Prasad R. Congenital hypothyroidism: current perspectives. Res Rep Endocr Disord. 2015;5:91-102. doi: 10.2147/RRED.S56402.

29. Gupta BM, Dayal D. Pediatric type 1 diabetes research in the 21 st century: a scientometric review. Pediatr Endocrinol Diabetes Metab. 2020;26(3):132-9. doi: 10.5114/pedm.2020.98165, PMID 32901470.

30. Dayal D, Gupta BM, Gupta S. Quantitative and qualitative assessment of Indian research yield in type 1 diabetes during 1996-2019. J Diabetol. 2021;12(1):28-35.

31. Baas J, Schotten M, Plume A, Côté G, Karimi R. Scopus as a curated, highquality bibliometric data source for academic research in quantitative science studies. Quant Sci Stud. 2020;1(1):377-86. doi: 10.1162/qss_a_00019.

32. AIRyalat SAS, Malkawi LW, Momani SM. Comparing bibliometric analysis using PubMed, Scopus, and Web of Science databases. J Vis Exp. 2019;152(152):e58494. doi: 10.3791/58494, PMID 31710021 